Universidade Federal de Santa Catarina (UFSC), Rod. Ulysses Gaboardi, km 3, Campus Universitário, CEP 89520-000, Curitibanos, SC, Brasil

2Faculdade Integrado de Campo Mourão, Campo Mourão, PR, Brasil 3Universidade Federal da Fronteira Sul (UFFS), Chapecó, SC, Brasil

* autor correspondente 凶 bottega.elb@gmail.com

\title{
Efeitos da profundidade e velocidade de semeadura na implantação da cultura do milho
}

\author{
Effects of depth and speed seeding on implementation of \\ maize crop
}

Eduardo Leonel Bottega ${ }^{*}$, Roberson Braido², Hugo von Linsingen Piazzetta ${ }^{3}$,

Antonio Mendes de Oliveira Neto ${ }^{2}$, Naiara Guerra ${ }^{2}$

RESUMO: Um dos fatores capazes de aumentar a produtividade de uma lavoura é a qualidade da operação de semeadura. A velocidade de deslocamento do conjunto trator-semeadora, associado à profundidade de deposição das sementes influenciam de forma direta o estabelecimento de um bom estande de plantas em campo. Este trabalho foi realizado no município de Mamborê/PR, no ano de 2012 e teve por objetivo avaliar a influência de três velocidades de deslocamento $\left(3,0,6,0\right.$ e 9,0 $\left.\mathrm{km} \mathrm{h}^{-1}\right)$ e duas profundidades de semeadura $(0,03$ e $0,05 \mathrm{~m})$ na implantação de uma lavoura de milho. As variáveis analisadas foram o índice de velocidade de emergência (IVE) e os espaçamentos entre plantas (múltiplo, falho e aceitável). A profundidade de semeadura não influenciou as variáveis estudadas, independente da velocidade de deslocamento adotada. A maior velocidade de deslocamento ocasionou redução da média de espaçamento normal entre plantas.

PALAVRAS-CHAVE: Emergência de plântulas, espaçamento entre plantas, semeadura direta, latossolo.
ABSTRACT: One of the factors that increase the productivity of a crop is the quality of the sowing operation. The travel speed of the tractor-seeder, associated with the depth of seed deposition directly influence the establishment of a good stand of plants in the field. This work was conducted in the municipality of Mamborê/PR, in 2012 and aimed to evaluate the influence of three speeds (3.0, 6.0 and $9.0 \mathrm{~km} \mathrm{~h}^{-1}$ ) and two sowing depths $(0.03$ and $0.05 \mathrm{~m})$ in the implementation of a corn crop. The variables analyzed were the speed of emergence index (SEI) and plant spacing (multiple flawed and acceptable). The sowing depth did not influence the variables, regardless of the travel speed adopted. The higher travel speed caused reduced average normal spacing between plants.

KEYWORDS: Seedling emergence, plant spacing, no-tillage system, oxisol.

\section{Introdução}

A qualidade da semeadura de uma cultura é de fundamental importância para garantir um estande final adequado, e consequentemente, o sucesso da implantação da lavoura e uma boa produtividade (SCHMIDT et al., 1999). Inúmeras variáveis podem afetar a qualidade de semeadura, sendo a velocidade de semeadura uma das mais importantes (KURACHI et al., 2006).

Mantovani et al. (1999) observaram que o aumento da velocidade de deslocamento do conjunto trator e semeadora modifica a velocidade periférica do disco perfurado, causando danos mecânicos às sementes e comprometendo a ocupação das células e dos dedos preensores. Estudos conduzidos por Silva, Kluthcouski e Silveira (2000) demostraram que a 
uniformidade dos espaçamentos entre as sementes de milho (Zea mays) na linha de semeadura também é afetada pela velocidade de deslocamento, sendo considerada excelente para a velocidade de $3,0 \mathrm{~km} \mathrm{~h}^{-1}$, regular para 6,0 e $9,0 \mathrm{~km} \mathrm{~h}^{-1}$ e insatisfatória para $11,2 \mathrm{~km} \mathrm{~h}^{-1}$.

Mahl et al. (2004) após realizar ensaios variando a velocidade de semeadura, concluíram que, para as velocidades 4,4 e 6,1 km $\mathrm{h}^{-1}$ a eficiência na distribuição de sementes de milho, além de ser semelhante, é significativamente melhor que na velocidade de $8,1 \mathrm{~km} \mathrm{~h}^{-1}$. Observaram ainda que a maior velocidade de semeadura proporcionou menor percentual de espaçamentos normais e aumento no percentual de espaçamentos múltiplos e falhos, maior coeficiente de variação e pior índice de precisão, contudo, não interferiu na população inicial de plantas. Fey, Santos e Fey (2000) comprovaram que o aumento da velocidade na operação de semeadura de milho influenciou na uniformidade de distribuição longitudinal de plantas (distância entre plantas na mesma linha), porém não afetou a população final de plantas (estande) e a produtividade de grãos.

Outro fator que afeta o desenvolvimento das culturas, relacionado ao processo de semeadura, é a profundidade de deposição da semente. Normalmente, para o milho a semeadura se concentra entre 3 a $7 \mathrm{~cm}$ de profundidade, sendo a profundidade média adotada de $5 \mathrm{~cm}$. Caso essas sementes sejam semeadas em maior profundidade, poderá causar prejuízos à emergência das plântulas, decorrente do maior gasto de energia da plântula na emergência, com reflexos no vigor inicial da cultura (EMPRESA..., 1996).

Objetivou-se com este estudo avaliar a influência da velocidade de deslocamento do conjunto trator-semeadora e da profundidade de semeadura na implantação da cultura do milho (Zea mays) na região de Mamborê - PR.

\section{Material e Métodos}

$\mathrm{O}$ experimento de campo foi conduzido na Fazenda Alvorada, localizada no município de Mamborê - PR, com latitude $24^{\circ} 23^{\prime} 08.34^{\prime \prime}$ Sul, longitude $52^{\circ} 37^{\prime} 22.99^{\prime \prime}$ Oeste e altitude de $631 \mathrm{~m}$. O solo é caracterizado como LATOSSOLO VERMELHO Distroférrico (EMPRESA..., 2006). Segundo a classificação de Köppen, o clima da região é do tipo "Cfa", subtropical.

$\mathrm{Na}$ operação de semeadura, foi utilizada uma semeadoraadubadora PP solo, modelo 4000, composta por cinco linhas espaçadas em $0,90 \mathrm{~m}$. A máquina possui capacidade para armazenagem de $1.000 \mathrm{~kg}$ de adubo e $200 \mathrm{~kg}$ de semente. A largura útil de trabalho é de $4,5 \mathrm{~m}$. Na implantação do experimento, utilizou-se sulcador tipo facão. Os depósitos de adubo e sementes foram mantidos à meia carga durante a implantação do experimento. Para tracionar a semeadoraadubadora, utilizou-se um trator CBT, modelo 2600, 4×2 TDA, com 79,4 kW (108 cv) de potência no motor.

A semeadura foi realizada no dia 4 de outubro de 2012, seguindo zoneamento agroclimático da cultura do milho no Paraná, conforme a classificação do híbrido escolhido. A densidade populacional utilizada foi de 70 mil plantas por hectare. Para fertilização, utilizou-se $300 \mathrm{~kg}$ de adubo pré - formulado (08 - 20 - 20). Foi semeado híbrido simples de milho da Pioneer (30F53 HX), de ciclo precoce ( 870 unidades de grau dia - GDU), grão duro avermelhado, população de 70 mil plantas por hectare, recomendado para a época e o local onde se realizou o experimento.

As variáveis testadas foram: 3 velocidades de deslocamento do conjunto mecanizado e 2 profundidades de semeadura. $\mathrm{O}$ delineamento experimental utilizado foi o de blocos ao acaso, em esquema fatorial $3 \times 2$ (três velocidades de deslocamento e duas profundidades de semeadura), com quatro repetições. As velocidades testadas foram $3,6 \mathrm{e} 9 \mathrm{~km} \mathrm{~h}^{-1} \mathrm{e}$ as profundidades de semeadura de 3 e $5 \mathrm{~cm}$. As três velocidades combinadas com as duas profundidades compuseram 6 tratamentos.

Cada parcela experimental ocupou uma área de $90 \mathrm{~m}^{2}$ $(4,5 \times 20 \mathrm{~m})$, sendo a área total utilizada para o experimento equivalente à $2.160 \mathrm{~m}^{2}$. Avaliou-se, para cada tratamento, o índice de velocidade de emergência de plântulas (IVE) e a distribuição longitudinal de sementes. O IVE foi contabilizado utilizando o método proposto por Maguire (1962), onde o índice de velocidade de emergência de plântulas foi avaliado em um comprimento de 3 metros nas duas linhas centrais de cada parcela, totalizando 6 metros de avaliação. Excluiu-se 2 metros da bordadura de cada parcela para diminuir o erro experimental. A contagem das plântulas emergidas foi realizada, a cada dois dias até 16 dias após a semeadura. Para estimativa do IVE utilizou-se a Equação 1:

$I V E=\frac{E_{1}}{N_{1}}+\frac{E_{2}}{N_{2}}+\ldots \frac{E_{n}}{N_{n}}$

Em que,

IVE - índice de velocidade de emergência;

E1, E2, Em - número de plantas emergidas, na primeira, segunda,..., última contagem;

$\mathrm{N} 1, \mathrm{~N} 2, \mathrm{Nn}$ - número de dias da semeadura á primeira, segunda,..., última contagem.

A distribuição longitudinal de sementes foi avaliada por meio do método de verificação de germinação das sementes, dos espaçamentos entre as plantas, bem como, a germinação obtida para a qualidade de sementes depositadas foi realizada 16 dias após a semeadura. Levantou-se o número de ocorrência de deposição de múltiplos, falhos e aceitáveis e compararam-se esses números com as recomendações agronômicas do espaçamento entre sementes para a cultura utilizada (milho: espaçamento de $12,5-16,5 \mathrm{~cm})$, conforme proposto por Mialhe (1996).

Os dados referentes aos parâmetros avaliados foram submetidos ao teste de normalidade de Shapiro-Wilk, à análise de variância e as médias testadas pelo teste de Tukey a 5\% de probabilidade.

\section{Resultados e Discussão}

Na Tabela 1 são apresentados os parâmetros estatísticos representativos da análise descritiva das variáveis estudadas. Todas as variáveis apresentaram distribuição normal. Observou-se elevado coeficiente de variação. Pimentel-Gomes e Garcia (2002) destacam que elevados CV(\%) indicam 
baixa uniformidade dos parâmetros avaliados, no caso do experimento, estes valores podem ser explicados em decorrência da variação de dimensões das sementes, da altura de queda e da velocidade de queda no tubo de sementes, pois esses fatores afetam a distribuição longitudinal das plantas. Teixeira et al. (2009) verificaram que o efeito da velocidade não atua isoladamente, outros fatores, como a dimensão e a forma das sementes e do orifício do disco, também influenciam o percentual de enchimento.

São apresentados na Tabela 2, os valores médios para a variável IVE em função das diferentes profundidades de deposição de sementes e velocidades de semeadura. Observou-se que não houve diferença significativa entre os tratamentos, não diferindo na profundidade e na velocidade de semeadura, corroborando com estudos realizados por Vian (2012). Durante a avaliação do IVE (16 dias) a distribuição de chuva foi normal para o período, não sendo observados períodos de seca. A interação profundidade de semeadura e velocidade de semeadura também não foi significativa.

Pode-se observar na Tabela 2 que, o IVE embora não significativo, apresentou uma tendência de queda com o aumento da velocidade de semeadura. Fato contrário pode ser observado para as diferentes profundidades que, mesmo não significativo, teve um aumento no IVE. Segundo Ortolani, Banzato e Bortoli (1986) a melhor resposta para o índice de velocidade de emergência das plântulas em maiores profundidades de semeadura, possivelmente, deve-se ao efeito da temperatura do solo, que por sua vez, condicionará o ambiente térmico favorável ao estabelecimento inicial da planta.

Silva et al. (2008) destacam que a profundidade de deposição das sementes pode afetar sua germinação, condicionada pela temperatura, teor de água, peculiaridades da semente, propriedades físicas e químicas do solo, clima e manejo da cultura, dentre outros fatores. Koakoski et al. (2007) e Weirich Neto et al. (2007) afirmam que, quanto maior a profundidade de deposição, maior o consumo de energia na emergência, além de prejuízos causados por baixas temperaturas e baixos níveis de oxigênio; já quanto menor a profundidade, maior a susceptibilidade da semente a estresses hídricos. Fornasiere Filho (1992) atenta ao fato de que a semeadura profunda (acima de $7 \mathrm{~cm}$ ) pode retardar a emergência das plântulas e, em certos casos, impedi-la totalmente, pela incapacidade das plântulas alongarem-se até alcançarem a luz.

Avaliando-se as variáveis plantas falhas (PF); plantas duplas (PD) e espaçamento normal (EN), cujos valores médios são apresentados na Tabela 3, observou-se que não houve diferença significativa entre as profundidades de semeaduras, porém dentre as velocidades estudadas a velocidade de $9 \mathrm{~km} \mathrm{~h}^{-1}$ apresentou resultado agronomicamente inferior.

Observa-se na Tabela 3 que a profundidade de deposição de sementes não influenciou significativamente as variáveis estudadas. As velocidades de $3 \mathrm{~km} \mathrm{~h}^{-1}$ e $6 \mathrm{~km} \mathrm{~h}^{-1}$, apresentaram melhor distribuição para espaçamento normal entre plantas. Resultado inferior foi observado para a velocidade de deslocamento equivalente à $9 \mathrm{~km} \mathrm{~h}^{-1}$.
Mahl et al. (2004), trabalhando com eficiência de distribuição de sementes em diferentes velocidades na semeadura da cultura do milho observaram que a maior velocidade proporcionou menor percentual de espaçamentos normais e aumento no percentual de espaçamentos múltiplos e falhos. Estudos realizados por Santos et al. (2000), concluíram que o aumento da velocidade de 3 para $7 \mathrm{~km} \mathrm{~h}^{-1}$ reduziu significativamente o percentual de espaçamentos normais.

Mahl et al. (2001) destacam que o aumento da velocidade de deslocamento compromete o desempenho das semeadorasadubadoras quanto à distribuição longitudinal de sementes. Dias et al. (2009) avaliando a distribuição de sementes de milho e soja em função de diferentes velocidades de trabalho, observaram que o aumento da velocidade de deslocamento

Tabela 1. Estatística descritiva das variáveis estudadas. Mamborê - PR, 2012

\begin{tabular}{lcccc}
\hline \multicolumn{1}{c}{ Parâmetros } & $\mathbf{I V E}^{\mathbf{1}}$ & $\mathbf{P F}^{2}$ & $\mathbf{P D}^{\mathbf{3}}$ & $\mathbf{E N}^{4}$ \\
\hline Normalidade* & Sim & Sim & Sim & Sim \\
Média & 11,31 & 12,13 & 6,54 & 13,66 \\
Desvio padrão & 1,63 & 2,46 & 2,41 & 5,69 \\
Variância & 2,65 & 6,02 & 5,83 & 34,47 \\
C.V. $(\%)^{* *}$ & 14,49 & 19,56 & 35,53 & 34,79 \\
\hline
\end{tabular}

*Teste de Shapiro-Wilk a 5\% de probabilidade; **C.V. Coeficiente de variação; IVE: Índice de velocidade de emergência; ${ }^{2} \mathrm{PF}$ : Plantas falhas; ${ }^{3} \mathrm{PD}$ : Plantas duplas; ${ }^{4}$ EN: Espaçamento normal.

Tabela 2. Teste de médias para a variável índice de velocidade de emergência (IVE), em função de diferentes profundidades e velocidades de semeadura. Mamborê - PR, 2012.

\begin{tabular}{cc}
\hline \multicolumn{3}{c}{ Profundidade (m) } \\
\hline 0,03 & $10,68 \mathrm{a}$ \\
0,05 & $11,94 \mathrm{a}$ \\
\hline 3 & Velocidade $\left(\mathbf{k m ~ h}^{-1}\right)$ \\
\hline 6 & $11,89 \mathrm{a}$ \\
9 & $11,03 \mathrm{a}$ \\
\hline
\end{tabular}

As médias seguidas pela mesma letra na coluna não diferem estatisticamente entre si pelo teste de Tukey ao nível de 5\% de probabilidade.

Tabela 3. Teste de médias para as variáveis, plantas falhas (PF); plantas duplas (PD); e espaçamento normal (EN), em função de diferentes profundidades e velocidades de semeadura. Mamborê - PR, 2012.

\begin{tabular}{cccc}
\hline Profundidade $(\mathbf{m})$ & PF & PD & EN \\
\hline 0,03 & $12,41 \mathrm{a}$ & $6,25 \mathrm{a}$ & $14,0 \mathrm{a}$ \\
0,05 & $11,83 \mathrm{a}$ & $6,83 \mathrm{a}$ & $13,3 \mathrm{a}$ \\
\hline Velocidade $\left(\mathbf{k m ~ h}^{-1}\right)$ & $\mathbf{P F}$ & $\mathbf{P D}$ & $\mathbf{E N}$ \\
\hline 3 & $12,12 \mathrm{a}$ & $6,37 \mathrm{a} \mathrm{b}$ & $16,37 \mathrm{a}$ \\
6 & $11,12 \mathrm{a}$ & $5,12 \mathrm{~b}$ & $16,12 \mathrm{a}$ \\
9 & $13,12 \mathrm{a}$ & $8,12 \mathrm{a}$ & $8,50 \mathrm{~b}$ \\
C.V. $(\%)$ & 19,56 & 35,53 & 34,79 \\
\hline
\end{tabular}

As médias seguidas pela mesma letra na coluna não diferem estatisticamente entre si pelo teste de Tukey ao nível de $5 \%$ de probabilidade. 
não reduziu significativamente a população de plantas para ambas as culturas estudadas. Esse resultado é explicado pelos autores pelo fato da diminuição no número de espaçamentos aceitáveis serem compensada pelo número no espaçamento múltiplo, contudo, espaçamentos falhos podem ocasionar a redução da produtividade da cultura do milho.

Na cultura do milho plantas falhas proporcionam a presença de mato competição interespecífica, na qual os organismos envolvidos utilizam o mesmo recurso, resultando em prejuízo mútuo ao desenvolvimento. As plantas daninhas, assim como todas as outras, exigem água, nutrientes e luz para sobreviver, havendo diferenças entre espécies vegetais quanto à importância relativa da competição acima da superfície do solo. Este tipo de competição induz mudanças morfológicas nas plantas, como redução da espessura foliar e reduções na proporção de matéria seca de raízes em relação à parte aérea (BIANCHI; FLECK; DILLENBURG, 2006).

\section{Conclusões}

A profundidade de semeadura não influencia as variáveis estudadas, independente da velocidade de deslocamento adotada.

A maior velocidade de deslocamento ocasiona redução da média de espaçamento normal entre plantas.

Não há relação entre profundidade de semeadura e velocidade de deslocamento do conjunto trator e semeadoraadubadora para as variáveis estudadas nas condições em que foram realizados os ensaios.

\section{Referências}

BIANCHI, M. A.; FLECK, N. G.; DILLENBURG, L. R. Partição da competição por recursos do solo e radiação solar entre cultivares de soja e genótipos concorrentes. Planta Daninha, Viçosa, v. 24, n. 4, p. 629-639, 2006. http://dx.doi.org/10.1590/S010083582006000400003

DIAS, V. O. et al. Distribuição de sementes de milho e soja em função da velocidade e densidade de semeadura. Ciência Rural, Santa Maria, v. 39, n. 6, p. 1721-1728, 2009. http://dx.doi.org/10.1590/ S0103-84782009005000105

EMPRESA BRASILEIRA DE PESQUISA AGROPECUÁRIA EMBRAPA. Recomendações técnicas para o cultivo do milho. 2. ed. Brasília: EMBRAPA-SPI, 1996. 204 p.

EMPRESA BRASILEIRA DE PESQUISA AGROPECUÁRIA EMBRAPA. Sistema brasileiro de classificação de solos. 2. ed. Rio de Janeiro: EMBRAPA-SPI, 2006.

FEY, E.; SANTOS, S. R.; FEY, A. Influência da velocidade de semeadura sobre a produtividade de milho (Zea mays L.). In: CONGRESSO BRASILEIRO DE ENGENHARIA AGRÍCOLA, 29., 2000, Fortaleza. Anais... Fortaleza: Sociedade Brasileira de Engenharia Agrícola, 2000. 1 CD-ROM.

FORNASIERE FILHO, D. A cultura do milho. Jaboticabal: FUNEP, 1992. 273 p.
KOAKOSKI, A. et al. Desempenho de semeadora-adubadora utilizando-se dois mecanismos rompedores e três pressões da roda compactadora. Pesquisa Agropecuária Brasileira, Brasília, v. 42, n. 5, p. 725-731, 2007.

KURACHI, S. A. H. et al. Avaliação tecnológica de semeadoras e ou adubadoras: Tratamento de dados de ensaio influência da velocidade de deslocamento na semeadura do milho. Engenharia Agrícola, Jaboticabal, v. 26, n. 2, p. 520-527, 2006.

MAGUIRE, J. D. Speed of germination-aid in selection and evaluation for seedling emergence and vigor. Crop Science, Madison, v. 2, p.176-177, 1962.

MAHL, D. et al. Demanda energética e eficiência da distribuição de sementes de milho sob variação de velocidade e condição de solo. Engenharia Agrícola, Jaboticabal, v. 24, n. 1, p. 150-157, 2004. http://dx.doi.org/10.1590/S0100-69162004000100017

MAHL, D. et al. Distribuição longitudinal e profundidade de deposição de sementes de uma semeadora-adubadora de plantio direto em função da velocidade e mecanismo sulcador. In: CONGRESSO BRASILEIRO DE ENGENHARIA AGRÍCOLA, 30., 2001, Foz do Iguaçu. Anais... Cascavel: Sociedade Brasileira de Engenharia Agrícola, 2001. CD-ROM.

MANTOVAnI, E. C. et al. Desempenho de dois sistemas distribuidores de sementes utilizados em semeadoras de milho. Pesquisa Agropecuária Brasileira, Brasília, v. 34, n. 1, p. 93-98, 1999.

MIALHE, L. G. Máquinas agrícolas: ensaio e certificação. Piracicaba: Fundação de Estudos Agrários, 1996. 722 p.

ORTOLANI, A. F.; BANZATO, D. A.; BORTOLI, N. M. Influência da profundidade e da compactação do solo, na emergência e desenvolvimento do sorgo granífero (Sorghum bicolor L. Moench). In: CONGRESSO BRASILEIRO DE ENGENHARIA AGRÍCOLA, 15., 1986, Botucatu. Anais... Botucatu: Sociedade Brasileira de Engenharia Agrícola, 1986. p. 24-32.

PIMENTEL-GOMES, F.; GARCIA, C. H. Estatística aplicada a experimentos agronômicos e florestais: exposição com exemplos e orientações para uso de aplicativo. Piracicaba: Fealq, 2002.

SANTOS, S. R. et al. Diagnóstico do processo de semeadura da soja (Glycine max L. MERRILL): Estudo de multi casos. In: CONGRESSO BRASILEIRO DE ENGENHARIA AGRICOLA, 29., 2000. Fortaleza. Anais... Fortaleza: Sociedade Brasileira de Engenharia Agrícola, 2000. p. 1-4.

SCHMIDT, A. V. et al. Semeadora adubadora para plantio direto. Porto Alegre: Emater, 1999. 56 p.

SILVA, J. G.; KLUTHCOUSKI, J.; SILVEIRA, P. M. Desempenho de uma semeadora adubadora no estabelecimento e na produtividade da cultura do milho sob plantio direto. Scientia Agrícola, Piracicaba, v. 57, n. 1, p. 7-12, 2000. http://dx.doi.org/10.1590/ S0103-90162000000100003

SILVA, R. P. et al. Efeito da profundidade de semeadura e de rodas compactadoras submetidas a cargas verticais na temperatura e no teor de água do solo durante a germinação de sementes de milho. Ciência e Agrotecnologia, Lavras, v. 32, n. 3, p. 929-937, 2008. http://dx.doi.org/10.1590/S1413-70542008000300034

TEIXEIRA, S. S. et al. Distribuição longitudinal de sementes de milho com dosador de disco horizontal operando com uma ou 
duas saídas de sementes. Ciência Rural, Santa Maria, v. 39, n. 8 , p. 2417-2421, 2009. http://dx.doi.org/10.1590/S010384782009005000186

VIAN, T. Utilização de diferentes mecanismos dosadores de sementes e velocidades de deslocamento na implantação de uma lavoura de milho (Zea mays). 2012. 16 f. Trabalho de Conclusão de Curso (Agronomia)-Faculdade Integrado de Campo Mourão, Campo Mourão, 2012.

WEIRICH NETO, P. H. et al. Profundidade de deposição de semente de milho na região dos campos gerais, Paraná. Engenharia Agrícola, Jaboticabal, v. 27, n. 3, p. 782-786, 2007. http://dx.doi. org/10.1590/S0100-69162007000400022

Recebido: 01 nov. 2013 Aprovado: 13 out. 2014 